\title{
Editorial 2013: Five hundred times Thank You!
}

\section{Fabrice Duparc}

Published online: 3 January 2013

(C) Springer-Verlag France 2012

The editorial activity of our journal Surgical and Radiologic Anatomy continued to increase in 2012. Two parameters may reflect the hard job of the editorial board: more than 500 manuscripts have been submitted, and the impact factor is now 1.056! The constant parallel increasing of these two values within the past decade leads to warmly thank all the associate editors who contributed to achieve this new position of SRA in the field of the scientific publishing about clinical anatomy, but also the 690 reviewers who completed manuscripts analysis out of 1,248 that had been requested. Few years ago, we were used to publish the list of the reviewers of the past year, but it is not possible to do that anymore regarding the number of anatomists and clinicians who participated actively. This editorial is especially dedicated to them.

2013 will be a new great year in Anatomy with the EACA congress in Lisbon, Portugal, in June. Like in Padova 2011, it will be a joint congress with the British Association of Clinical Anatomists, and we are sure that this will be a large and interesting meeting.

On behalf of the Editorial Board, I wish you a very nice and happy new year 2013.

Fabrice Duparc, MD-PhD, Editor in chief. 